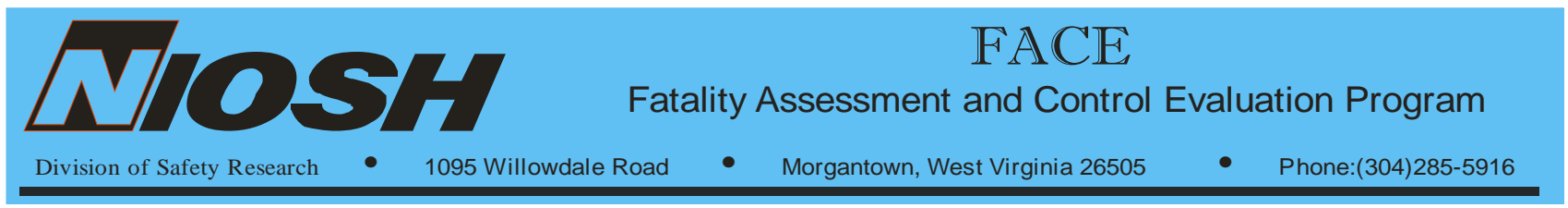

FACE Report Number 2013-05

June 22, 2017

\title{
Worker Killed When a Section of Pipeline Crashed Through Excavator Cab and Struck Him in the Chest During a Tandem Lift-West Virginia
}

\section{SUMMARY}

On Sunday, December 16, 2012, at approximately 6:37 p.m., a 44-year-old male excavator operator died after being struck in the chest by a section of 16-inch gas pipeline. Two excavator operators were using a tandem lift ${ }^{1}$ procedure to transport a 128-foot section of the pipe from a construction area (top of hill) to an installation area (bottom of hill). The two excavators were on the right side of the pipe, and the operators needed to maneuver around the pipe prior to moving it down to the installation area. Both excavators were attached to the pipe with slings, approximately 20 feet from each end of the pipe. The lead operator lowered his end, detached from the pipe, and positioned his excavator on the left side of the pipe; once on the left side, he reattached to the pipe and raised it off the ground. The operator of the rear excavator attached at the opposite end (rear) of the pipe, then raised the pipe off the ground to cab height and maneuvered the excavator around the end of the pipe while swinging the boom of the excavator. When the pipe was in line with the excavator cab, the pipe plunged through the front windshield, entering the cab and striking the operator in the chest. Police, emergency medical services, and the medical examiner arrived, and the excavator operator was pronounced dead at the scene.

\section{CONTRIBUTING FACTORS}

Key contributing factors identified in this investigation include:

- Lack of tandem lifting procedures.

- Communication between operators and ground workers.

- Visibility of the work area including the lifted load.

\section{Fatality Assessment and Control Evaluation (FACE) Program}

The National Institute for Occupational Safety and Health (NIOSH), an institute within the Centers for Disease Control and Prevention (CDC), is the federal agency responsible for conducting research and making recommendations for the prevention of work-related injury and illness. In 1982, NIOSH initiated the Fatality Assessment and Control Evaluation (FACE) Program. FACE examines the circumstances of targeted causes of traumatic occupational fatalities so that safety professionals, researchers, employers, trainers, and workers can leam from these incidents. The primary goal of these investigations is for NIOSH to make recommendations to prevent similar occurrences. These NIOSH investigations are intended to reduce or prevent occupational deaths and are completely separate from the rulemaking, enforcement and inspection activities of any other federal or state agency. Under the FACE program, NIOSH investigators interview persons with knowledge of the incident and review available records to develop a description of the conditions and circumstances leading to the deaths in order to provide a context for the agency's recommendations. The NIOSH summary of these conditions and circumstances in its reports is not intended as a legal statement of facts. This summary, as well as the conclusions and recommendations made by NIOSH, should not be used for the purpose of litigation or the adjudication of any claim. For further information, visit the program website at www.cdc.gov/niosh/face/ or call toll free at 1-800-CDC-INFO (1-800-232-4636).

${ }^{1} \mathrm{~A}$ tandem lift is the simultaneous use of two or more pieces of powered lifting equipment; a tandem lift is a critical lift if the lifted load is to be moved laterally [Work Safe BC 2012]. 


\section{RECOMMENDATIONS}

NIOSH investigators concluded that, to help prevent similar occurrences, employers should:

- Implement a comprehensive safe work procedure for tandem lifting operations and a sitespecific safety plan/lift plan.

- Provide worker training that includes hazard recognition and avoidance of unsafe conditions.

- Implement an effective method of communication between excavator operators and ground workers.

- Ensure use of adequate lighting during all work activities.

\section{INTRODUCTION}

At approximately 6:37 p.m. on December 16, 2012, a 44-year-old excavator operator was fatally injured when a 128-foot section of 16-inch pipeline struck and entered the cab of his excavator, crushing him in the chest. NIOSH learned of the incident from the Occupational Safety and Health Administration (OSHA). The West Virginia area office of OSHA conducted an investigation of the fatality. In August of 2014, a NIOSH safety and occupational health specialist, a safety research engineer, and a guest researcher met with the OSHA compliance officer who investigated the incident and reviewed the case file. The medical report contained the official cause of death provided by the emergency response personnel who pronounced the operator dead at the scene. Contact with the site Manager was attempted with no return response.

\section{EMPLOYER}

The employer is a gas and oil pipeline contractor, which operates throughout the United States. The company was hired to install 20,000 feet of 16-inch pipe and 42,000 feet of 10-inch pipe. The project was scheduled for completion in April of 2013. The company had only been working on the project for approximately 3 weeks when the incident occurred.

\section{WRITTEN SAFETY PROGRAMS and TRAINING}

All the excavator operators had completed the appropriate training and were considered experts on excavating operations. According to OSHA, the employer had not established lifting procedures for using two excavators during a lifting operation.

\section{WORKER}

The company hired the 44-year-old operator 12 days prior to the incident. He had 20 years of work experience operating heavy equipment including excavators. He was hired for his expertise and experience. He had been a member of the International Union of Operating Engineers since July 23, 2008. On the day of the incident, the on-site foreman assigned the operator to replace the regular excavator operator. The 44-year-old operator was assigned to this task based upon his knowledge and experience in lifting operations.

\section{INCIDENT SCENE}

The employees were working at dark at the time of the incident, using the lights of the excavators as well as lights from a pickup truck to illuminate the work area. The excavator 
operators were communicating via hand signals, and the victim's excavator cab door was open to allow verbal communication if there were any questions with the given signals.

The project consisted of installing 20,000 feet of 16-inch pipe and 42,000 feet of 10-inch pipe and was scheduled for completion in April 2013. The 128-foot section of pipe was to be transferred 800 feet down a $45 \%$ grade to the creek bed and installed in the prepared trench at the creek crossing.

\section{WEATHER}

At the time of the incident, the temperature was approximately $56^{\circ} \mathrm{F}$ with $80 \%$ humidity. Winds were recorded at $10.4 \mathrm{mph}$, with scattered clouds and no precipitation [Weather Underground 2012]. The weather is not believed to have been a factor in this incident.

\section{INVESTIGATION}

On Sunday, December 16, 2012, two excavator operators were making a tandem lift of a 16inch-diameter, 128-foot-long section of pipe with two excavators. The pipe was constructed from three 40-foot pipe joints and one tube turn. According to the OSHA report, the pipe weighed approximately 7,024 lbs. The tandem lift was needed to transport the constructed section of pipe 800 feet down a $45 \%$ grade to the creek bed for installation in the prepared trench at the creek crossing.

The lead excavator was a Caterpillar 329D (Photo 1). The rear excavator was a Caterpillar 336E [Caterpillar 2009] (Photo 2). Both excavators were attached to the pipe via a nylon continuous strap. The lead excavator was attached to the hook on the bucket of the excavator (Photo 3 ). The bucket of the rear excavator had been removed, and a Caterpillar 10-ton swivel mat hook with safety latch was installed to the end of the dipper stick using two shackles (Photo 4). 


Fatality Assessment and Control Evaluation
Investigation Report \#2013-05

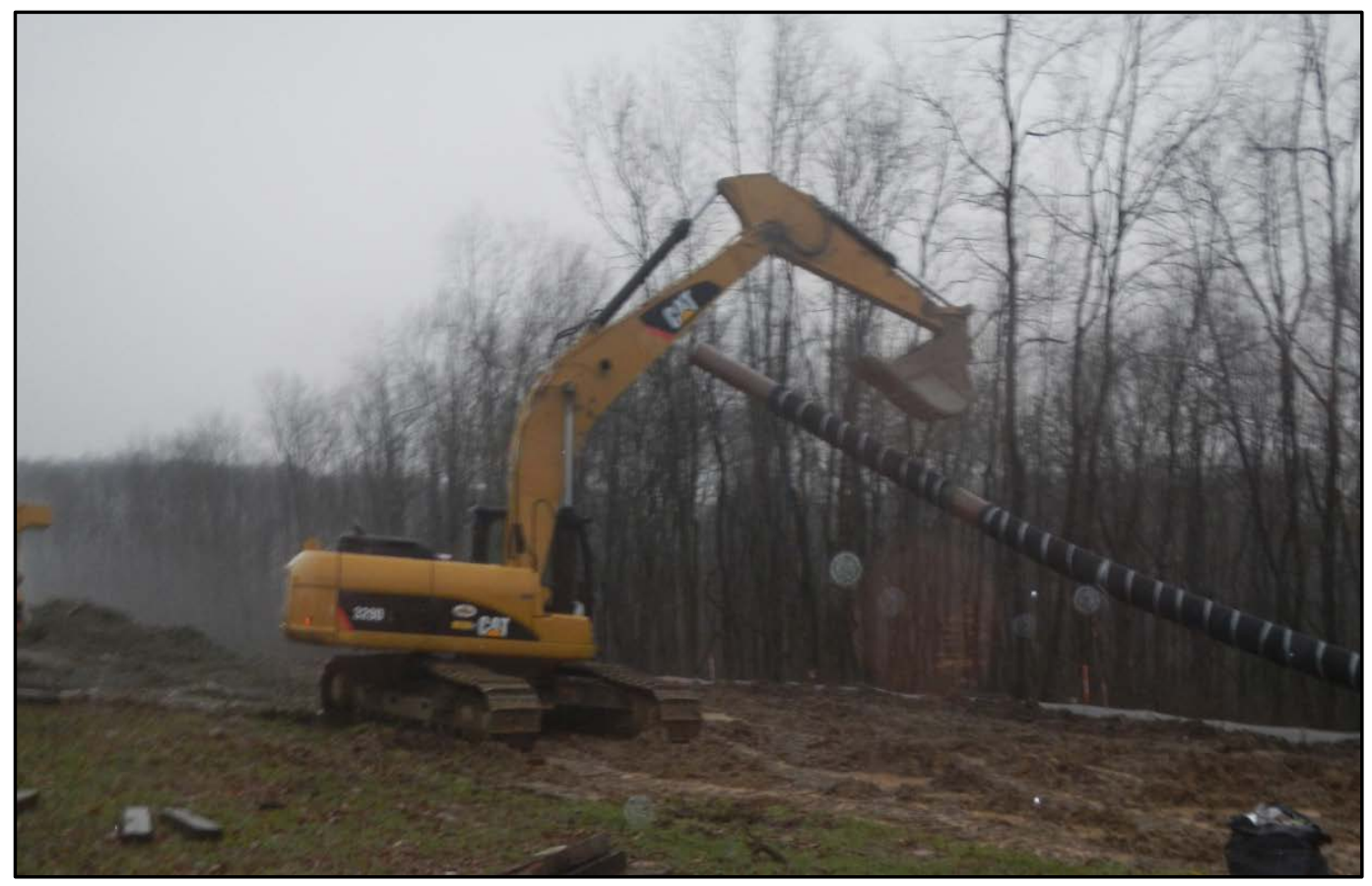

Photo 1. Lead excavator.

(Photo courtesy of WV OSHA.)

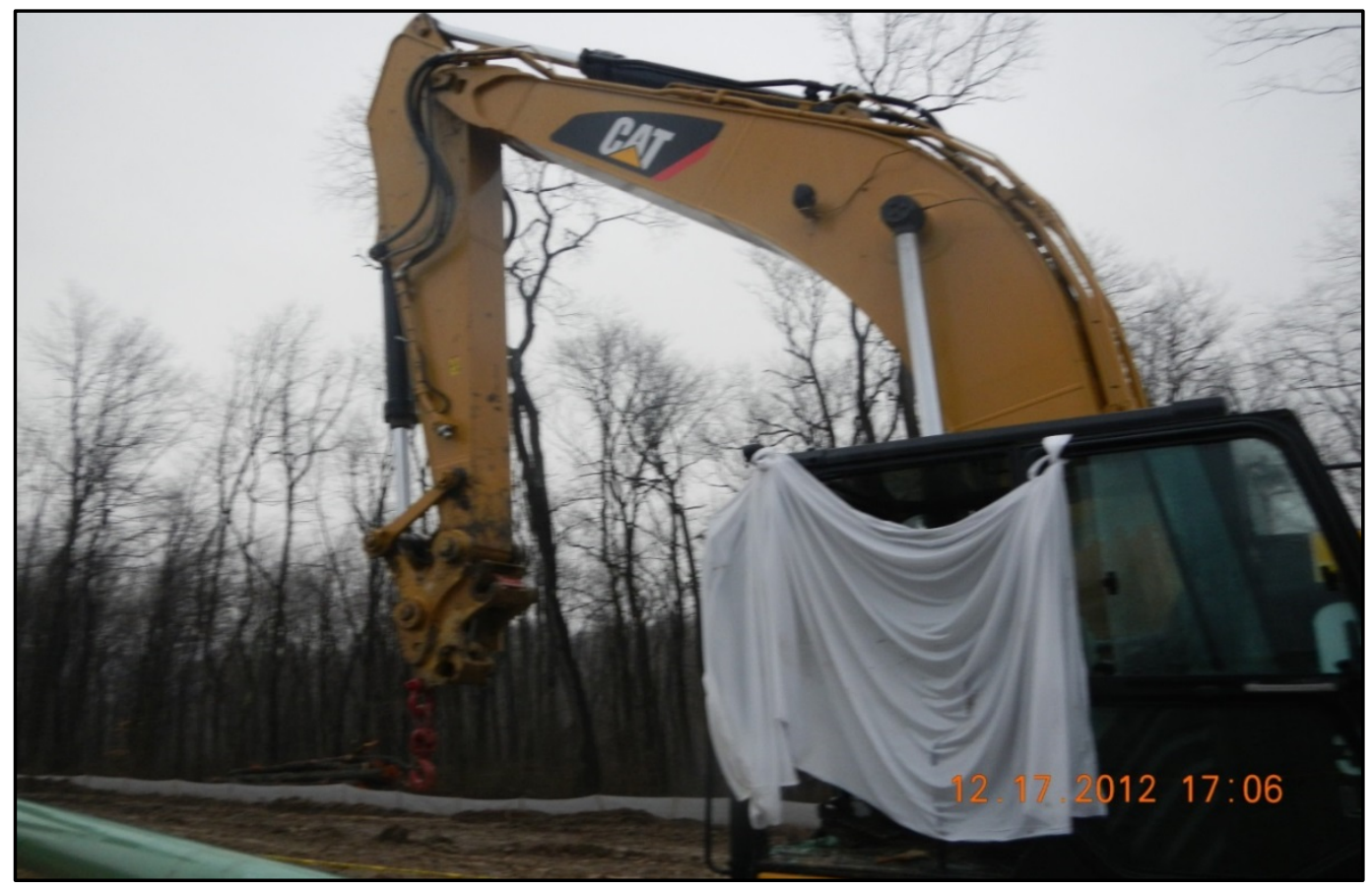

Photo 2. Rear excavator (victim).

(Photo courtesy of WV OSHA.) 


Fatality Assessment and Control Evaluation
Investigation Report \#2013-05

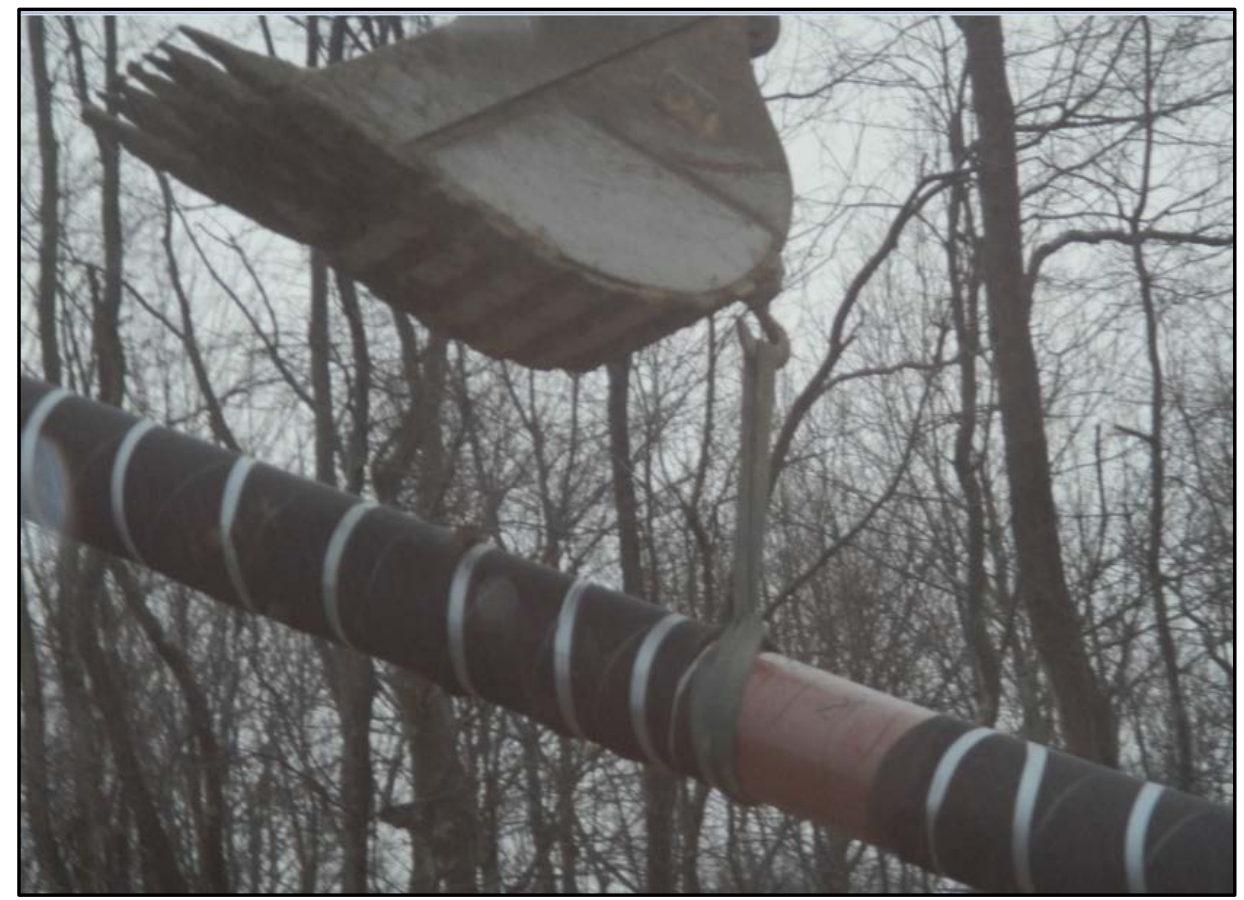

Photo 3. Lead excavator; pipe attached to the hook on the bucket of the excavator. (Photo courtesy of WV OHSA.)

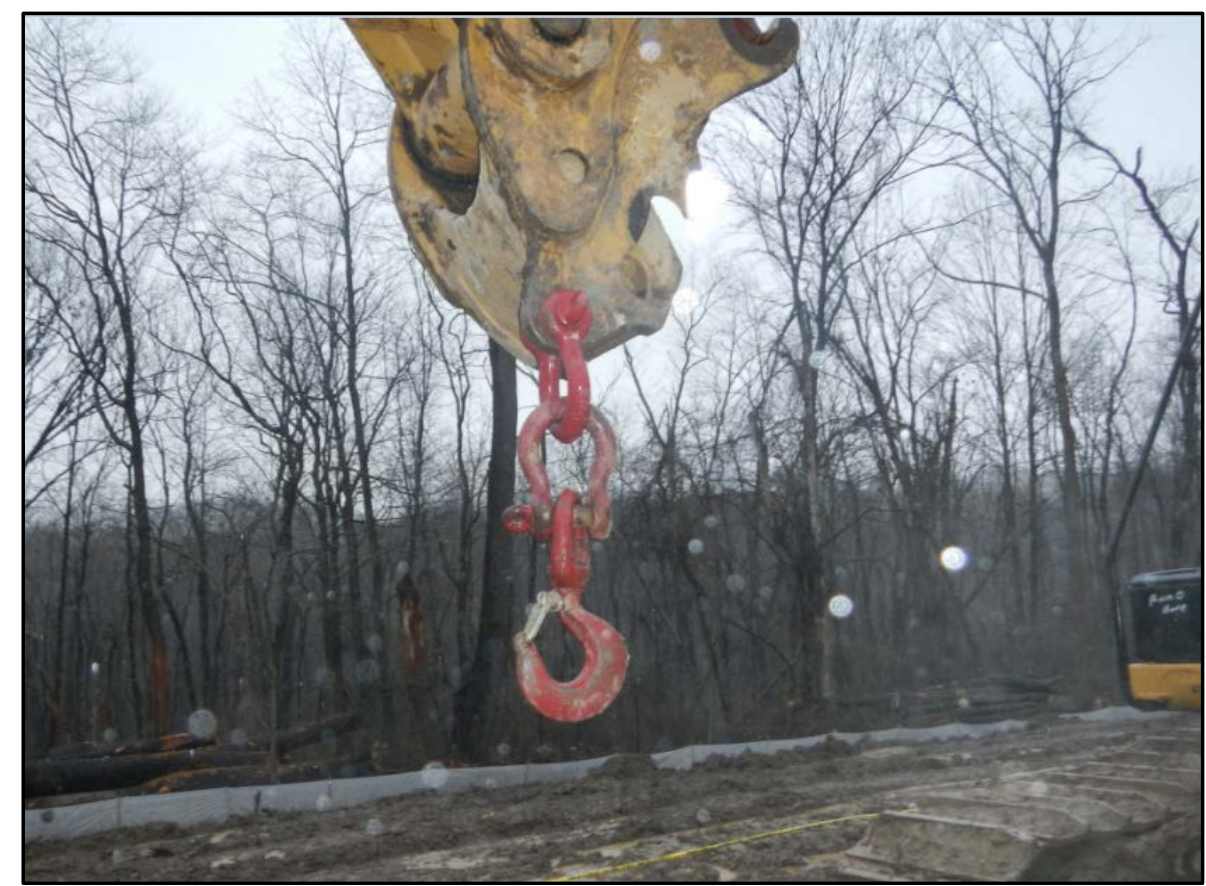

Photo 4. Rear excavator; Caterpillar 10-ton swivel mat hook with safety latch installed to the end of the dipper stick using two shackles.

(Photo courtesy of WV OSHA.) 


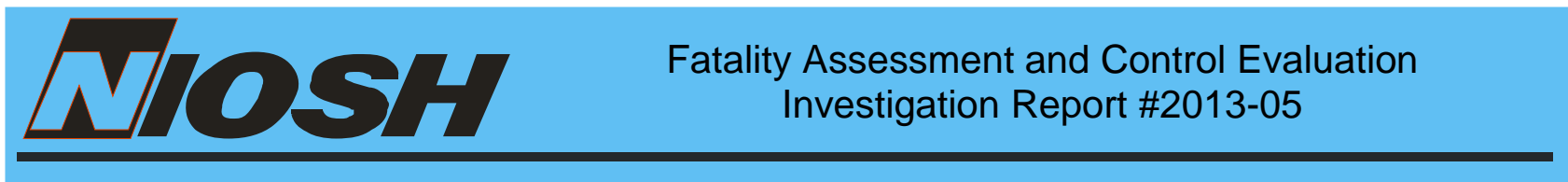

The 128-foot section of pipe was constructed and sitting on wooden skids and needed to be transferred from the working side of the right-of-way to the ditch side of the right-of-way. Both excavators were on the right side of the pipe when they first attached to it. The lead excavator was attached to the pipe approximately 21 feet from the end while the rear excavator (victim) was attached approximately 21 feet 10 inches at the opposite end (Figure 1).

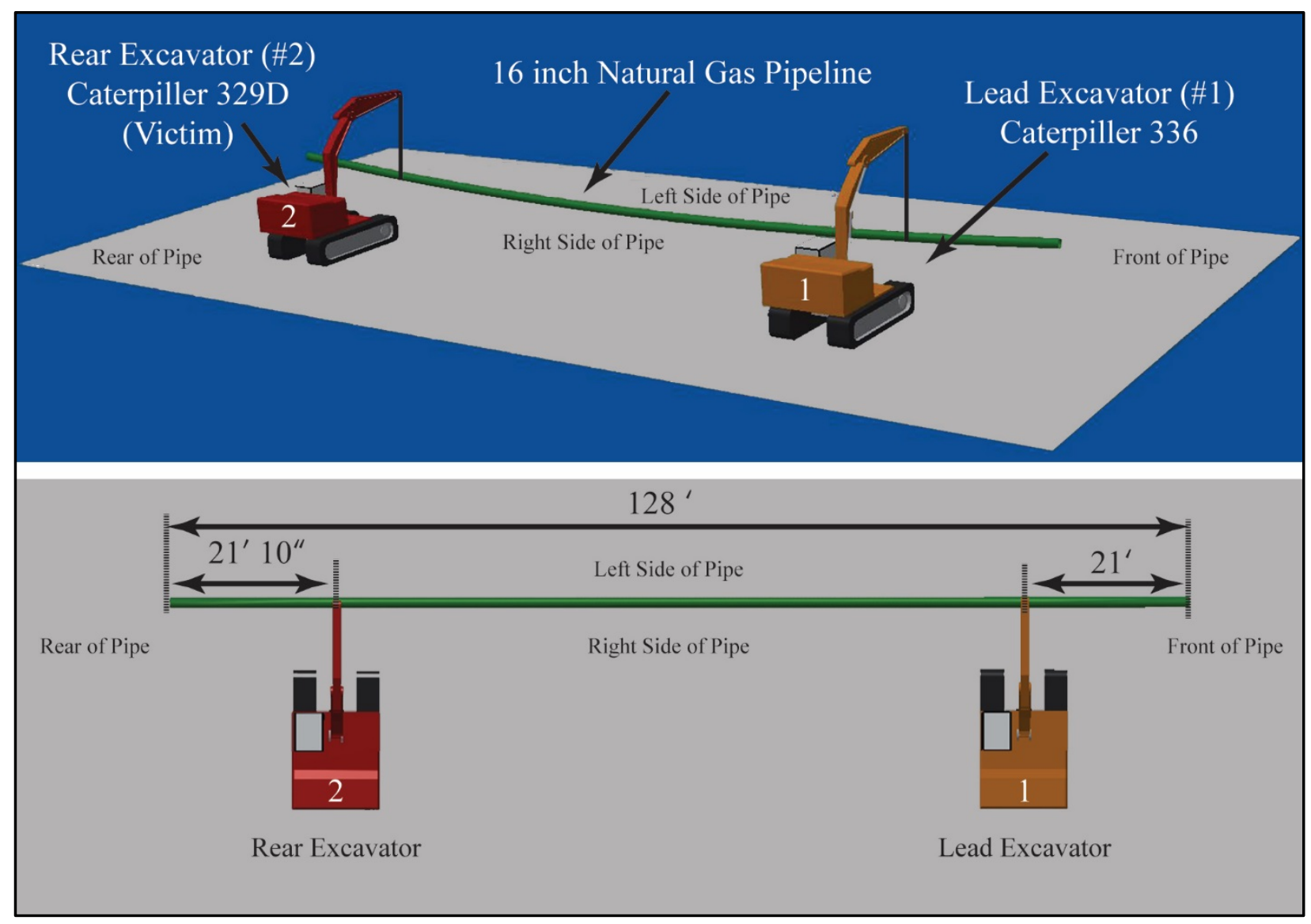

Figure 1. Drawing of excavator position in reference to pipeline.

Both operators picked up the pipe at the same time. The lead excavator operator backed away from the skids and then lowered the pipe to the ground; the rear excavator operator kept his end of the pipe up in the air. A coworker unhooked the lead excavator from the pipe to allow the lead operator to move his excavator around to the opposite side of the pipe and re-attach (Figure 2). Once the lead excavator was in its new position, the coworker reattached it to the pipe and the lead excavator operator again raised the pipe. 


\section{Fatality Assessment and Control Evaluation}

Investigation Report \#2013-05

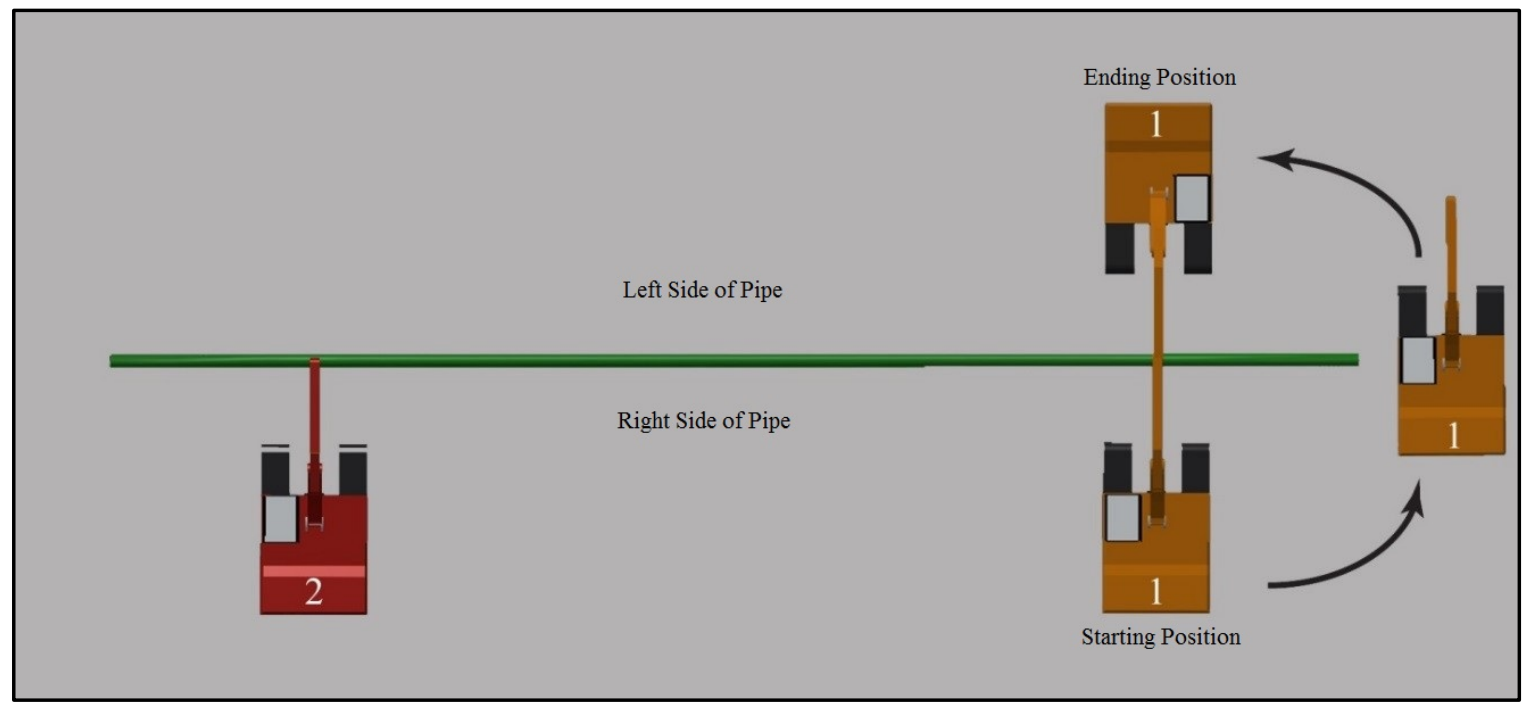

Figure 2. Drawing showing movement of the lead excavator.

The rear excavator operator was attempting to reposition his excavator to the end of the pipe while staying attached to the pipe. The steps that were actually taken are not known but can be conjectured based upon the start and end positons of the rear excavator. In order to maneuver the excavator around the end of the pipe, the boom and the arm would have to be in an almost fully extended position to maintain an optimal attachment point at the end of the bucket/strap connection. The tracks would have to be turned parallel with the pipe, and the excavator would have to tram to the end of the pipe while rotating the operator's cab of the excavator and adjusting the height of the attachment point. When the excavator reached the end of the pipe, the pipe would have been in the direct path with the operator's cab window.

The lead excavator operator started swinging his boom to his left, taking the pipe away from the rear excavator. The rear excavator operator started swinging his end of the pipe to his right towards the lead excavator. The lead excavator operator said that he could tell that the rear excavator operator was swinging because he could see him at first and he could tell by the position of his choker (nylon strap). The chief inspector for the gas company observed that as the rear excavator was swinging the end of the pipe around, the pipe cleared the front of the rear excavator by approximately 3 feet. Once the rear excavator reached the end of the pipe, the operator turned his tracks from perpendicular to the pipe end to direct alignment with the pipe (Figure 3). 


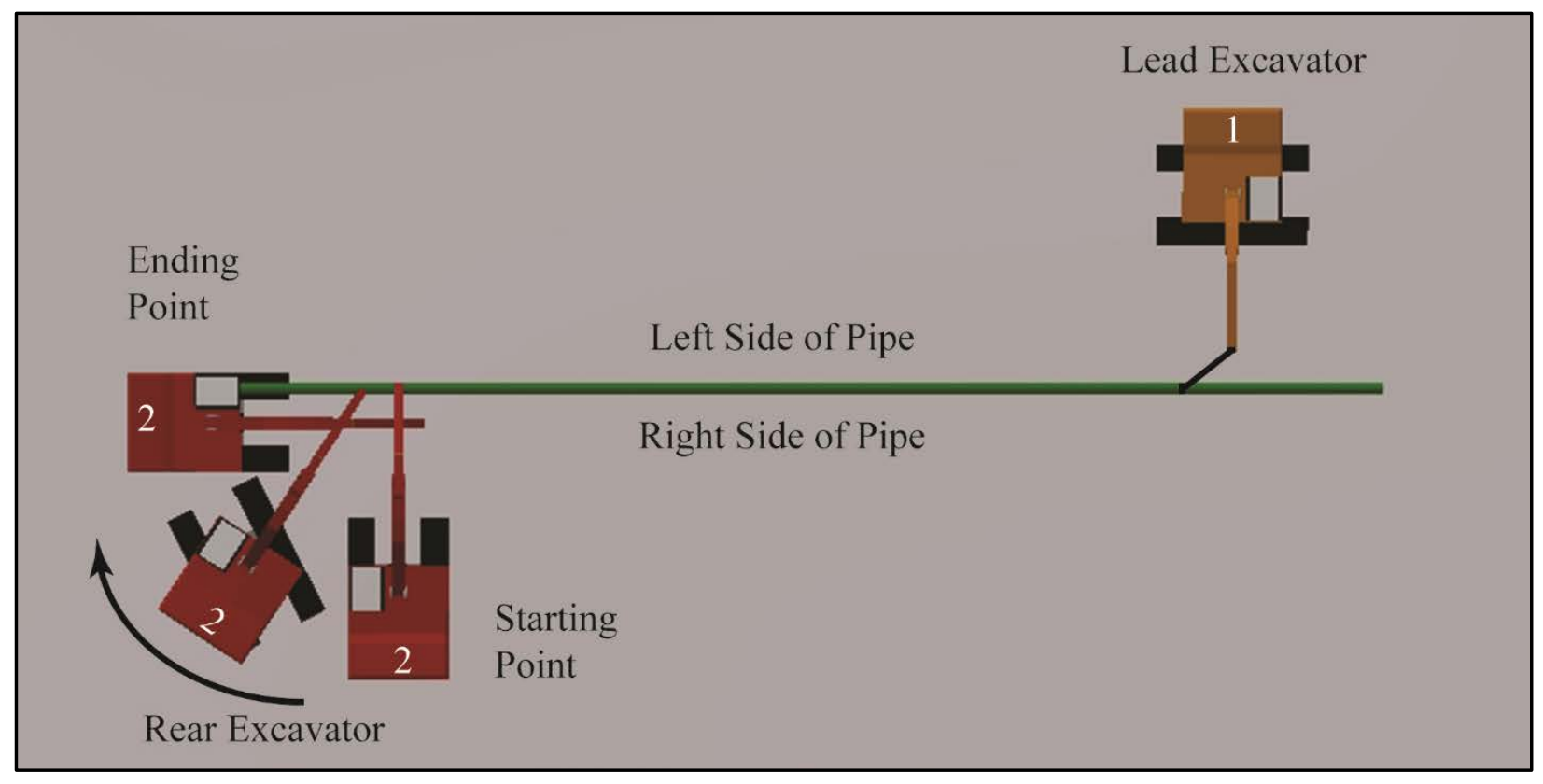

Figure 3. Drawing showing movement of rear excavator (victim) while attached to the pipe.

The lead excavator operator said that everything was going smoothly, then all of a sudden his excavator was jerked toward the rear excavator. The pipe pulled the lead excavator through the swing brake, and the operator reported that the lead excavator was pulled approximately 3 inches toward the rear excavator. The end of the pipe that was supported by the rear excavator was pulled through the front glass of the cab approximately 50 inches, striking the rear excavator operator in the chest (Figure 4). The travel control, which controlled the force to pull the bucket through the ground, was punched backward and bent to the side. The fuse box, which was located behind the operator's seat, was damaged and may have caused the machine to stop running.

After the situation was assessed, the lead excavator operator attempted to pull the pipe back out of the rear excavator cab, but the pipe would not move. It was noted that the rear excavator was not running but the key was still in the on position and that the strap supporting the pipe was running parallel to the pipe instead of hanging down at 90 degrees. The operator was found with his right hand up to his chest and his left hand down toward the controls. Coworkers attempted to knock the chokers back down the pipe to relieve pressure on the operator but were unsuccessful. Emergency medical services, who had been contacted and had arrived on site, instructed the employees to stop efforts to remove the pipe until the medical examiner arrived. Once the medical examiner arrived, employees removed the travel controls from the excavator to relieve the pressure from the stick and the pipe. The operator was pronounced dead at the scene and then transported to a local hospital. 

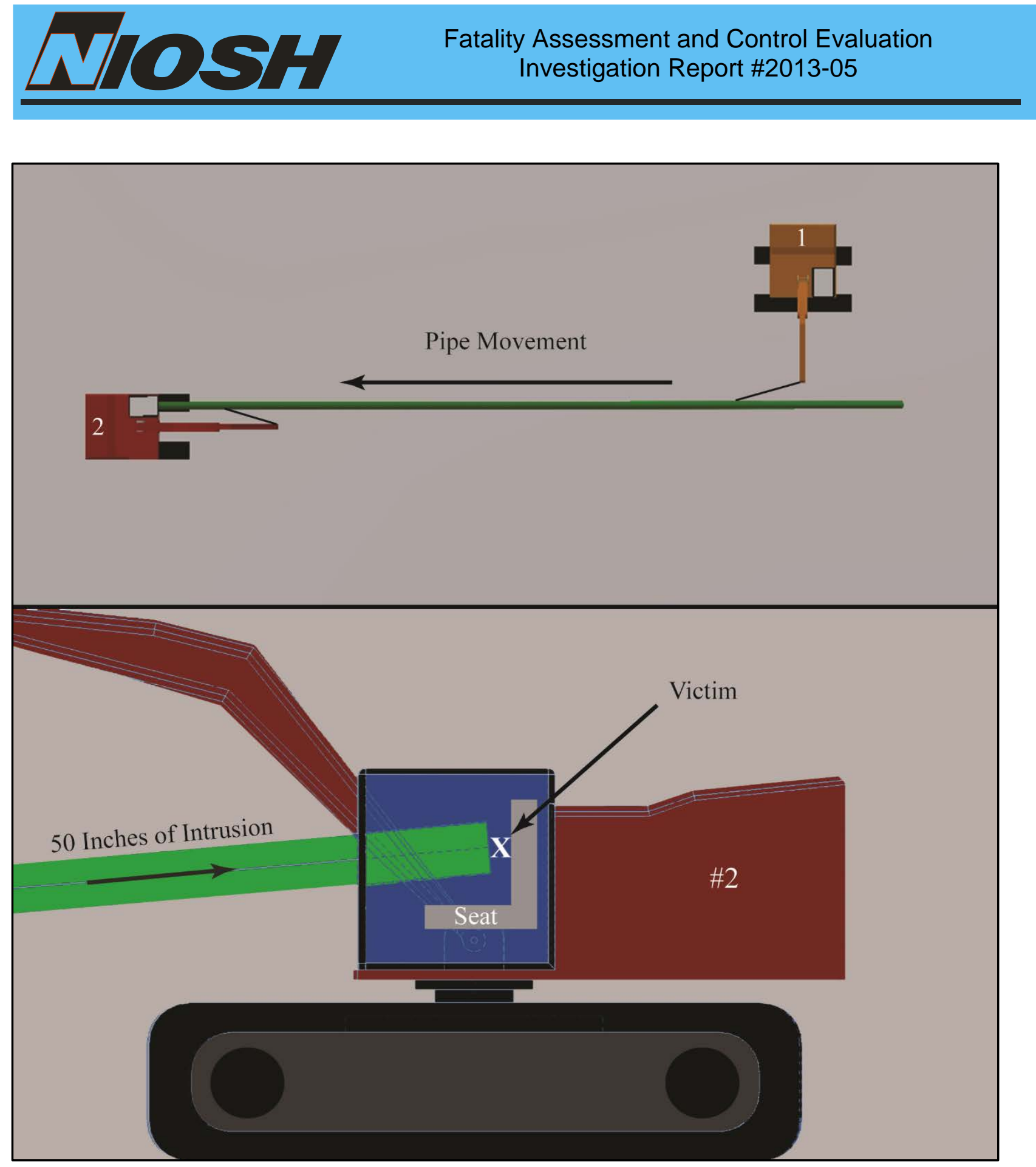

Figure 4. Drawing showing pipe movement into the rear excavator cab. 

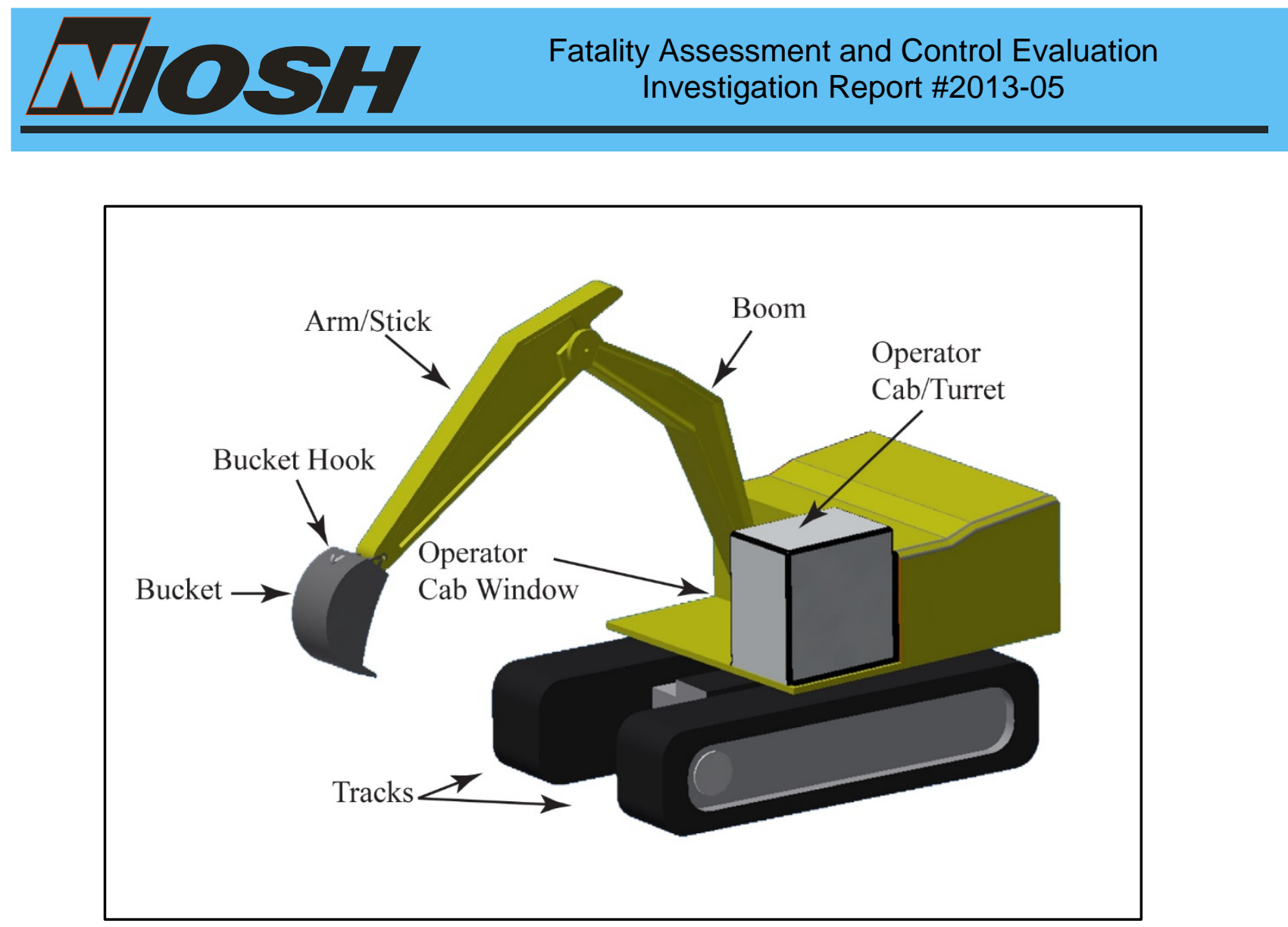

Figure 5. Excavator components.

\section{ADDITIONAL INFORMATION}

The excavator has two main sections - the undercarriage and the house. The undercarriage includes the tracks, track frame, and the final drives, which have a hydraulic motor and gearing that provide the drive to the individual tracks. The house is attached to the undercarriage by way of a center pin that allows the machine to turn 360 degrees. The main boom of an excavator is attached to the house, and the stick or "dipper arm" is attached to the boom (Figure 5). In this incident, the final drive for the excavator tracks was positioned to the front of the excavator. With the final drive positioned to the front, the hand controls in the cab would be pulled back to move the machine forward. Because of this, when the pipe entered the cab and struck the drive control bars, it caused the excavator to move forward. Had the final drive been positioned to the rear of the excavator when the pipe entered the cab, the excavator would have traveled backward.

The front window of the excavator cab was not equipped with any guarding. In the timbering and demolition industry, guarding is normally over the front glass of excavators. Guarding over the front glass is not normally used on excavators in the gas pipeline industry because the operators need the largest viewing area possible to view all the workers and equipment they are working near [OSHA 1970].

OSHA's inspection determined that the boom of the rear excavator had inadvertently pulled back and sent the end of the pipe into the operator's cab striking him. The precise cause of the arm pulling the pipe back toward the cab could not be determined. However, the complexity of the task that was attempted, as described above, could be a contributing factor. 
During the OSHA investigation, excavator operators at the site stated that they had experienced control difficulties with the excavators. The machines had on several occasions exhibited boom and stick movement without receiving control input from the operator. According to a factory service bulletin, dated September 11, 2012, "An improved stick regeneration valve is now used on certain 336E excavators” [Caterpillar 2012]. Hydraulic system warm-up procedures should always be followed as stated in the manufacturer's operation and maintenance manual [Caterpillar 2009]. "Operating a machine prior to completing these procedures can result in valve spools sticking or seizing, affecting the machine operation. The clearance between the stem and the valve bore of the stick regeneration valve has been changed. This change reduces the chance of the valve sticking if the machine is operated prior to the completion of the hydraulic system warm-up procedures stated in the operation and maintenance manual [Caterpillar 2012].” Following the incident, the excavator was removed from service and secured until it could be tested. The testing was conducted on April 10, 2013, based on a protocol developed by Caterpillar. The test found the excavator to be operating properly. It was possible that a malfunction of the regenerative valve on the excavator could have caused the incident, although the testing did not reveal this as a problem.

\section{CONTRIBUTING FACTORS}

Occupational injuries and fatalities are often the result of one or more contributing factors or key events in a larger sequence of events that ultimately result in the injury or fatality. NIOSH investigators identified the following unrecognized hazards as key contributing factors in this incident:

- Lack of tandem lifting procedures.

- Communication between operators and ground workers.

- Visibility of the work area including the lifted load.

\section{CAUSE OF DEATH}

Medical evidence obtained from the state medical examiner's office showed no evidence of the incident being secondary to any medical event or condition, with cause of death being blunt force trauma to the chest.

\section{RECOMMENDATIONS/DISCUSSION}

\section{Recommendation \#1: Employers should implement a comprehensive safe work procedure for tandem lifting operations and a site-specific safety plan/lift plan.}

Discussion: In this incident, the employer did not have a written procedure in place for a safe work method for tandem lifting operations. Prior to allowing a worker to operate an excavator, employers should ensure that the operator receives proper training for each required task. It is also important that employers obtain and keep the operation and safety manuals from equipment manufacturers and require operators to periodically review the manuals and follow manufacturer's instructions and requirements when operating the machinery (e.g., correct engine warm up procedures) [Caterpillar 2009]. In this case, the excavator operators were considered 
expert operators, however the lack of procedures or written policies to follow for tandem lifting could have been a contributing factor in the incident.

There was no documented lift plan. The complexity of coordinating the maneuvering of the equipment around the pipe while attached proved the need for a lift plan. The distance of the slings from the lifting apparatus to the load should have been calculated and reviewed prior to attachment. A lift plan would ensure the load is not swung directly in front of the operator's cab, safely positioning them away from the load. An example of steps in a lift plan for this case would be to have the excavators detach from the pipe, maneuver their excavators around to the opposite side of the pipe, then reattach while safely positioned away from any potential swinging motion of the load.

Excavators used with chains, slings, or other rigging to lift suspended loads are not covered by OSHA crane and derrick standards [OSHA 1970]. However, as exemplified by this incident, when lifting loads using excavators, workers are exposed to hazards similar to those associated with hoisting operations using cranes, in this case being struck by uncontrolled hoisted loads.

"NIOSH and others have identified certain types of hoisting operations that require special considerations to ensure worker safety. In the crane and rigging community the term critical lift ${ }^{2}$ is commonly used to describe these situations” [NIOSH 2006].

Included among these situations are when two or more cranes simultaneously lift the same load.

Tandem lifts with excavators should be treated as critical lifts. Tandem lifts require the use of two or more excavators/cranes, and a lifting plan should be developed and discussed prior to such lifts. Critical factors should be considered in the lifting plan to include curvature of the pipe, stability and weight capacities of the excavators, lifting points, length and positions for slings, and the excavator's position [Safety Info, no date]. Other critical factors that should be considered include height of the lift, standard operating procedures for repositioning the equipment, and location of equipment before moving the lifted object.

\section{Recommendation \#2: Employers should provide worker training that includes hazard recognition and avoidance of unsafe conditions.}

Employers should conduct a job hazard analysis to determine if operators are experienced and/or trained in tandem lift procedures. A job hazard analysis consists of a review of each job to identify potential hazards and to design actions and procedures to eliminate or control the identified hazards. The operator's competence can only be achieved through training and experience and determined through assessment; these activities should be recorded in the operator's training file. Lifting operations should be carried out under the direction of a competent person. ${ }^{3}$ The competent person engaged in this type of work should be aware of the

\footnotetext{
${ }^{2}$ In OSHA's steel erection standard, 29 CFR 1926 subpart R, critical lift is defined as “a lift that (1) exceeds 75 percent of the rated capacity of the crane or derrick, or (2) requires the use of more than one crane or derrick.”

${ }^{3} \mathrm{An}$ OSHA "competent person" is defined as "one who is capable of identifying existing and predictable hazards in the surroundings or working conditions that are unsanitary, hazardous, or dangerous to employees, and who has authorization to take prompt corrective measures to eliminate them" [OSHA 1993].
} 
current regulations, the industry's best practices, and their company's procedures and/or safe systems of work. According to Shapiro et. al [2000], when two pieces of machinery are used to lift a single object, the risk is more than double due to the disproportionality in the interaction of the machinery with each other. A formal written lift plan is advised and, at a minimum, should set out the positions of each machine and the load at the start of the operation [Shapiro et al. 2000].

In this instance, the alignment of the rear excavator in direct alignment with the pipe created an unsafe condition because any longitudinal swinging of the pipe placed the operator at high risk of the pipe entering into the cab.

\section{Recommendation \#3: Employers should implement an effective method of communication between excavator operators and ground workers.}

Discussion: An appropriate method of communication, such as use of two-way radios, should be established prior to operations. It is critical to have adequate means of communication for operating excavators during tandem (critical) lifting procedures. Equipment operators should be able to see and hear one another. Sufficient lighting is also critical, especially when communicating via hand signals [OSHA 1993].

In this case, a ground worker was using hand signals at dark as a means of communication. The excavator cab doors were opened to ensure the operators could see and hear any command given. However, while maneuvering the machines around the pipe, the open door may not have always been facing the ground worker giving the signals. This task would have been especially difficult while trying to control the machinery as the operator had to multitask and keep his eyes on the location of the load in order to see what the other operator was doing, as well as interpret the hand signals being given.

\section{Recommendation \#4: Employers should ensure use of adequate lighting during all work activities.}

Discussion: Although illumination measurements were not recorded, it was noted that work was being conducted at dark in an area illuminated by the lights of the two excavators and a pickup truck. Adequate lighting of the worksite is vital for the workers to function and communicate in a safe manner. Inadequate illumination can obscure hazards such as proximity of an operator's cab to a load, load movement, uneven ground conditions, and proximity of workers on foot, and thereby dramatically increase worker exposure to these hazards. The Occupational Safety and Health Administration (OSHA) regulations require a minimum illumination of construction areas [OSHA 1979]. The OSHA required minimum illumination standard for general construction areas is 5 foot-candles. Detailed information on work zone lighting can be also obtained from the National Cooperative Highway Research Program's document entitled Illumination Guidelines for Nighttime Highway Work [NCHRP 2003].

\section{DISCLAIMER}

Mention of any company or product does not constitute endorsement by the National Institute for Occupational Safety and Health (NIOSH). In addition, citations to Web sites external to NIOSH do not constitute NIOSH endorsement of the sponsoring organizations or their programs or 
products. Furthermore, NIOSH is not responsible for the content of these Web sites. All web addresses referenced in this document were accessible as of the publication date.

\section{REFERENCES}

Caterpillar [2009]. Caterpillar 336D operator manual. Peoria, IL: Caterpillar Corporate, http://s7d2.scene7.com/is/content/Caterpillar/C438864.

Caterpillar [2012]. An improved stick regeneration valve is now used on certain 336E excavators 5051. Peoria, IL: Caterpillar Inc.

NCHRP [2003]. Illumination guidelines for nighttime highway work. Washington, DC: Transportation Research Board, National Cooperative Highway Research Program (NCHRP), Report 498, http://onlinepubs.trb.org/onlinepubs/nchrp/nchrp_rpt_498.pdf.

NIOSH [2006]. Preventing worker injuries and deaths from mobile crane tip-over, boom collapse, and uncontrolled hoisted loads. Cincinnati, OH: U.S. Department of Health and Human Services, Centers for Disease Control and Prevention, National Institute for Occupational Safety and Health, DHHS (NIOSH) publication no. 2006-142, http://www.cdc.gov/niosh/docs/2006-142/pdfs/2006-142.pdf.

OSHA [1970]. 29 CFR 1910.212(a)(1). Occupational safety and health standards. Machinery and machine guarding. General requirements for all machines. Washington, DC: U.S. Department of Labor, Occupational Safety and Health Administration.

OSHA [1979]. 29 CFR 1926.26 Safety and health regulations for construction. Illumination. Washington, DC: U.S. Department of Labor, Occupational Safety and Health Administration.

OSHA [1993]. 29 CFR 1926.32(f). Safety and health regulations for construction. Definitions: competent person. Washington, DC: U.S. Department of Labor, Occupational Safety and Health Administration.

Safety Info [no date]. OSHA Critical Lift Safety Program. Guntersville, AL: SafetyInfo, https://www.safetyinfo.com/guests/Written-Safety-Programs/Critical-Lift-WorkplaceSafety-Program.htm.

Shapiro HI, Shapiro JP, Shapiro LK [2000]. Cranes and derricks. New York: McGraw-Hill.

Weather Underground [2012]. Weather history for KHLG. Atlanta, GA: The Weather Channel Interactive, Inc., http://www.wunderground.com/history/airport/KHLG/2012/12/16/DailyHistory.html.

\section{INVESTIGATOR INFORMATION}

This investigation was conducted by Nancy Romano, Safety and Occupational Health Specialist, Fatality Investigations Team, Surveillance and Field Investigation Branch, Division of Safety Research; Tony McKenzie, Protective Technology Branch, Division of Safety Research; and Rayed Almanei, Guest Researcher, West Virginia University Occupational Medicine Residency 


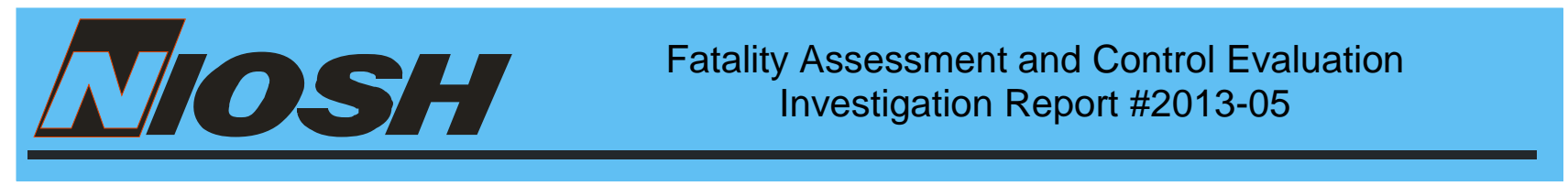

Program, Surveillance and Field Investigations Branch, Division of Safety Research. The report was co-authored by the investigators as well as by Melanie Moore, Occupational/Environmental Safety and Health Specialist, Fatality Investigations Team, Surveillance and Field Investigation Branch, Division of Safety Research.

\section{ACKNOWLEDGEMEMENT}

The NIOSH FACE Program would like to acknowledge assistance from OSHA for providing information for this investigation as well as Tony McKenzie, Protective Technology Branch, Division of Safety Research, for providing the figures and diagrams for the report. 